\title{
MEDIDAS DE ACTUACIÓN PARA LA PREVENCIÓN DE LA TOXIINFECCIÓN ALIMENTARIA
}

\author{
MARÍA ASCENSIÓN MAESTRE NARANJO* \\ SANTOS MUÑOZ ORTEGA** \\ (*) Especialista en Medicina del Trabajo. \\ Servicio de Prevención Hospital Universitario Puerta de Hierro. \\ Trabajo efectuado como miembro del Servicio Prevención de Winterthur \\ (**) Licenciado en Farmacia. \\ Jefe Servicio Catalogación CEMILFARDEF
}

\section{RESUMEN}

La toxiinfección alimentaria manifestada en forma de brotes tiene gran importancia desde el punto de vista epidemiológico.

Tras analizar su etiología se instauran las medidas preventivas y de seguridad en todos los procesos de manipulación de alimentos, así como las medidas de prevención para los trabajadores manipuladores de alimentos.

Se insiste de forma especial en la información y formación que deben recibir estos trabajadores, para concienciar y fomentar su responsabilidad y educación en las medidas higiénico sanitarias que favorecen su desarrollo.

En caso de producirse el brote se marcan las pautas a seguir para su notificación, por la gran importancia legal y epidemiológica que comporta.

\section{PALABRAS CLAVES}

Toxiinfección alimentaria, brote epidémico, prevención, notificación.

\section{ABSTRACT}

The alimentary toxiinfección manifested in form of buds has great importance from the epidemic point of view.

After analyzing their etiología the preventive measures they are established and of security in all the processes of manipulation of foods, as well as the measures of prevention for the hard-working manipulators of foods.

It is insisted in a special way in the information and formation that these workers should receive, to make aware and to foment their responsibility and education in the hygienic sanitary measures that favor their development.

In the event of taking place the bud the rules they are marked to continue for their notification, for the legal and epidemic great importance that behaves.

\section{KEY WORDS}

Alimentary Toxiinfección, sprout epidemic, prevention, notification. 


\section{TOXIINFECIONES ALIMENTARIAS}

Entendemos por Toxiinfección Alimentaría, el conjunto de enfermedades transmitidas por alimentos, que tienen como causa común, una serie de microorganismos patógenos y la exposición se ha producido durante un corto período de tiempo.

Consideramos Brote Epidémico la presentación de dos o más casos con un cuadro clínico semejante, que aparecen después de consumir el mismo alimento y el análisis epidemiológico implica a este alimento como fuente de la enfermedad.

\section{ETIOLOGÍA DE TOXIINFECCIONES ALIMENTARIAS}

Las causas más frecuentes de los brotes de enfermedades transmitidas por los alimentos suelen estar relacionadas con prácticas inadecuadas en el manejo o conservación de los alimentos por los manipuladores, entre las que podemos destacar como más comunes:

- Refrigeración inadecuada. (55,8\%).

- Lapso de 12 o más horas entre la preparación del alimento y su consumo $(30,8 \%)$

- Trabajadores con infecciones o portadores de patógenos que manipularon los alimentos $(24,2 \%)$

- Recalentamiento inadecuado (19,7\%)

- Mantenimiento de los alimentos preparados en lugares inadecuados o a temperaturas que favorecen el crecimiento microbiano $(16,2 \%)$

- Consumo de alimentos crudos o que contienen ingredientes contaminados. $(8,8 \%$.)

- Limpieza no adecuada del equipo de trabajo y utensilios $(5,8 \%)$

- Otros.

Por esta razón, cuando nos encontremos ante la presencia de un brote, debemos investigar sobre todo, si ha existido algún factor de los citados anteriormente, haciendo especial hincapié en aquellos factores que hayan podido favorecer la contaminación y multiplicación de los gérmenes, fallos en la conservación que hayan permitido la supervivencia de los gérmenes, o en los tratamientos térmicos culinarios con recalentamientos inadecuados de las comidas ya preparadas.

\section{MEDIDAS PREVENTIVAS Y SEGURIDAD EN LOS PROCESOS DE MANIPULACIÓN DE LOS ALIMENTOS}

Lo más recomendable es la aplicación del Sistema de Análisis de Peligros y Puntos de Control Crítico (Sistema APPCC), el cual nos permite identificar, evaluar y controlar peligros que son significativos para la seguridad alimentaria en los Puntos de Control Crítico (PCC), entendiendo estos como el punto, procedimiento, operación o etapa sobre los que se puede realizar el control. Esto es fundamental para prevenir, eliminar o reducir los riesgos de la seguridad alimentaria, a un nivel aceptable.

Posteriormente, la elaboración de un Plan APPCC, nos permite, por una parte, definir y establecer un protocolo de prácticas correctas de higiene, conforme a los principios del Sistema APPCC, orientado a asegurar el control de los riesgos identificados en materia de seguridad alimentaria. Por otra, definir su trazabilidad, o posibilidad de encontrar y seguir el rastro, a través de todas las etapas de producción, transformación y distribución de un alimento o sustancia destinada a ser incorporada a estos.

En definitiva, este procedimiento establece la sistemática a seguir por un Servicio de Prevención de Riesgos Laborales para prevenir, detectar y notificar una toxinfección alimentaria.

Este procedimiento ha sido elaborado para una empresa de la Comunidad de Madrid, por lo que según la legislación vigente en dicha comunidad se consideran prioritarias las siguientes medidas de actuación:

- Formación de trabajadores,

- Plan de mantenimiento de locales, instalaciones y equipos,

- Plan de limpieza y desinfección,

- Plan de control de plagas : desinsectación y desratización,

- Plan de control de abastecimiento de agua,

- Plan de buenas prácticas de fabricación y manipulación,

- Plan de trazabilidad.

- Plan de autocontrol de residuos químicos. 
A la hora de implantar un Sistema APPCC en cualquier empresa, es necesario la implicación directa y el compromiso explícito de la dirección de la institución, lo que debe llevar a la elaboración de un Plan APPCC, en el cual queden reflejados medidas concretas a adoptar, con la firma de la dirección del centro como aval de apoyo en cuanto a responsabilidad y compromiso por parte de ésta en su implantación.

Otra de las medidas importantes a tener en cuenta es que debe constituirse un equipo de trabajo multidisciplinar, integrado por un conjunto de personas con conocimientos y experiencia suficiente para garantizar con éxito tanto su puesta en marcha, como su desarrollo y mantenimiento posterior. Si esto no fuera posible, la medida más práctica sería externalizar este servicio de forma que se pueda contar con un equipo de expertos que elaboren la guía y garanticen el desarrollo y mantenimiento posterior del Plan APPCC.

Recomendaciones y secuencia de aplicación del Sistema APPCC:

1. Formación de un equipo APPCC

2. Descripción del producto.

3. Determinar la aplicación del sistema.

4. Elaboración de un diagrama de flujo.

5. Verificación in situ de un diagrama de flujo.

6. Enumeración de todos los peligros posibles. Ejecución de un análisis de peligros. Determinación de las medidas de control.

7. Identificación y determinación de los Puntos de Control Critico (PCC)

8. Establecer los límites críticos para cada PCC. PCC.

9. Establecer un sistema de vigilancia para cada

10.Establecer las medidas correctoras para las posibles desviaciones.

11. Establecer procedimientos de verificación.

12. Establecer un sistema de registro y documentación.

13. Aprobación por la dirección, que procederá a su implantación y puesta en marcha.

Por último, con vistas a un correcto funcionamiento, es necesario establecer un programa sis- temático de revisión del Plan, que permita adaptarlo a las posibles variaciones que confluyan en el sistema y requieran establecer modificaciones en alguno de los puntos del mismo o medidas correctoras de los procedimientos.

\section{MEDIDAS DE PREVENCIÓN DE RIESGOS PARA LOS MANIPULADORES DE ALIMEN- TOS}

Según la Ley 31/95, corresponde al empresario informar, formar y ofertar la vigilancia de la salud a todos los trabajadores a su servicio. Así, el Servicio de Prevención de Riesgos Laborales de la empresa deberá llevar a cabo actividades de información, formación y vigilancia de la salud, para todos los trabajadores de la empresa, pero en particular, y en aquellos casos que las actividades que desarrollan lo requieran, estableciendo programas específicos orientados a informar, formar y elaborar programas de vigilancia del salud de los trabajadores que se encuentran manipulando alimentos.

\section{Información para manipuladores de ali- mentos}

- Concienciar al trabajador de su responsabilidad en la salud de los colectivos para los que trabaja, fomentando la educación para la salud.

- Crear hábitos encaminados a fomentar la autovigilancia del trabajador en lo que se refiere a su propio estado de salud, de forma que cuando sospeche la existencia de cualquier enfermedad que pueda ser transmitida a través de los alimentos (conjuntivitis, gastroenteritis, amigdalitis o lesiones cutáneas), tengan información suficiente para saber que DEBEN COMUNICARLO INMEDIATAMENTE A SU SUPERIOR para establecer las medidas de valoración médica y si fuera necesario, proceder a separarlos de su actividad hasta su total curación (clínica y bacteriológica).

- Fomentar y crear hábitos higiénicos personales adecuados:

- Lavado de las manos con agua y jabón aclarándolas y secándolas con meticulosidad antes de empezar a trabajar, repetir esta operación siempre que sea necesario (des- 
pués de tocarse el pelo, la nariz, la boca o acudir al servicio).

- Máxima pulcritud en su higiene personal y en su indumentaria de trabajo.

- Utilización de ropa de color claro, prenda que cubra la cabeza y calzado adecuado a su función. Teniendo en cuenta que esta ropa solo podrá utilizarla como indumentaria de trabajo.

- Durante su trabajo está prohibido fumar, masticar, comer en el puesto de trabajo y estornudar o toser sobre los alimentos.

- Conocer cualquier práctica que pueda ser causa de contaminación de los alimentos, como la cata, que nunca debe hacerse con las manos, sino con una cuchara u otro instrumento y no podrá volver a utilizarse si no se ha lavado adecuadamente.

- No se deberán llevar efectos personales que puedan entrar en contacto con los alimentos (anillos, pulseras relojes u otros objetos).

- Las heridas en manos deberán cubrirse con apósito impermeable y utilizar guantes desechables.

- Informar sobre las reglas de oro de la adecuada manipulación, conservación y almacenamiento de los alimentos

- Escoger alimentos que hayan sido producidos y tratados mediante procedimientos higiénicos.

- Correcta desinfección y limpieza de alimentos.

- Cocción adecuada de los alimentos (la temperatura ha de llegar al menos a $70{ }^{\circ} \mathrm{C}$ en toda su masa).

- Consumir inmediatamente los alimentos cocinados. Se prepararán con la mínima antelación (promedio de 30 minutos, no debiendo superar los 45 minutos).

- Tener en cuenta que cuanto más tiempo se encuentren los alimentos expuestos a temperatura ambiente, mayor es el riesgo de multiplicación bacteriana, por lo que los alimentos deberán guardarse y conservarse adecuadamente, de forma que la temperatu- ra no descienda desde los $70^{\circ} \mathrm{C}$ hasta los $10^{\circ} \mathrm{C}$ en un periodo superior a las 2 horas.

- Calentamiento adecuado de los alimentos previamente cocinados, de forma que se llegue a ebullición siempre que sea posible y evitar cuando se pueda el recalentamiento a bajas temperaturas.

- Evitar siempre el contacto directo o a través de utensilios entre los alimentos crudos y los cocinados.

- Mantener escrupulosamente limpias todas las superficies de trabajo.

\section{Formación específica para manipuladores de alimentos.}

El RD 10/2001 de 25 de enero, establecen las normas relativas de los manipuladores de alimentos, autorización, control y supervisión de los centros y programas de formación de la Comunidad de Madrid. Se responsabiliza a la empresa de la formación de sus trabajadores, que deberá ser impartida por esta o a través de un centro de formación autorizado por la Consejería de Sanidad.

Durante este período el trabajador realizará sus funciones bajo control de personal cualificado en este campo. Una vez finalizada esta formación inicial, se realizará Formación Continuada, que deberá ser actualizará cuando se produzcan cambios estructurales, tecnológicos o de productos, y en todo caso, esta revisión y actualización de la formación se realizará al menos una vez cada cinco años.

\section{Vigilancia de la salud}

La principal herramienta para la vigilancia de la salud se centra en los reconocimientos médicos, que constan de una historia clínico-laboral, en la que además de los datos de anamnesis, exploración clínica, control biológico y pruebas complementarias en función de los riesgos identificados en el puesto de trabajo, se hará constar una descripción detallada del puesto de trabajo, el tiempo de permanencia en el mismo, riesgos en el puesto de trabajo, las medidas de prevención adoptadas y la utilización de equipos de protección individual. Igualmente debe hacerse constar una descripción detallada de los anteriores puestos de trabajo, riesgos presentes en los mismos y tiempo de permanencia en cada uno de ellos. 
En el caso de los manipuladores de alimentos debemos seguir un protocolo específico, que sigue los siguientes pasos:

\subsection{Cuestionario para verificar si el trabajador} presenta alguno de las siguientes situaciones:

- Haber padecido en algún momento fiebre tifoidea

- Haber tenido últimamente alguna patología gastrointestinal.

- Presentar lesiones cutáneas, forúnculos etc.

- Presentar conjuntivitis.

- Tener supuración de oídos

- Tener supuración de nariz.

- Estornudar o toser con frecuencia.

- Tener alguna herida en manos o brazos.

- Haber vivido en el extranjero (Para descartar países endémicos de paludismo o fiebre tifoidea).

- Haber viajado a algún país exótico en las últimas semanas.

- Ser fumador.

\subsection{Control biológico:}

- Hematología

- Bioquímica

- Análisis de orina

- Serología virus hepatitis A y B

3.3. Inmunización en función de serologías y vacunaciones previas; se ofertará al trabajador:

- Vacuna antitetánica

- Vacuna de hepatitis A y B

Una vez examinado el trabajador y en función de los resultados obtenidos se emitirá certificado de aptitud; se considerará Apto para el puesto de trabajo de manipulador de alimentos o No Apto, por encontrarse alterado alguno de los resultados de las exploraciones que nos indiquen algún riesgo a la hora de desarrollar su actividad laboral como manipulador de alimentos.

En este último supuesto, el trabajador será separado de su actividad laboral hasta que se encuentren superadas las causas que motivaron su retirada y por tanto, no exista riesgo para su salud y la de los demás.

\begin{tabular}{|c|c|}
\hline MICROORGANISMO & $\begin{array}{c}\text { REQUISITOS PARA RETORNO } \\
\text { AL TRABAJO }\end{array}$ \\
\hline Campylobacter & Ninguno \\
\hline Giardia lamblia & $\begin{array}{c}\text { Ninguno } \\
\text { Amebiasis }\end{array}$ \\
\hline Shigelérvalo de 48 horas
\end{tabular}

Tabla I. Infecciones más frecuentes y requisitos necesarios para reincorporación al puesto de trabajo en los manipuladores de alimentos 
Cuando un trabajador se reincorpora a su puesto de trabajo después de haber padecido una enfermedad infecto contagiosa deberá pasar un examen de salud en el que demuestre curación clínica y bacteriológica de su proceso, para lo cual deberá tenerse en consideración tanto las peculiaridades propias del agente específico como los requisitos necesarios para el retorno al puesto de trabajo (Tabla I).

En este grupo de trabajadores tiene especial importancia la hepatitis A, por el aumento de esta enfermedad y por la existencia de una vacunación adecuada que impide su desarrollo. Su transmisión es la vía

fecal-oral, facilitando su transmisión directa la mala higiene, el hacinamiento e indirectamente puede ocurrir a través del agua y de alimentos.

$\mathrm{Si}$ un trabajador manipulador de alimentos no está inmunizado correctamente de hepatitis A y enferma por este virus, se deberá proceder a su retirada de su lugar de trabajo, administrando gammaglobulina al resto de manipuladores de alimentos del mismo centro de trabajo, excepto aquellos que se encuentren inmunizados correctamente ( 3 meses previos).

También debemos de tener en cuenta que el período de máxima infectividad de la Hepatitis A, ocurre durante las dos semanas anteriores al inicio de la ictericia, si es que la presenta, por lo que el riesgo de máximo contagio suele ocurrir cuando todavía no se conoce que el manipulador padece la enfermedad.

Hasta 1984, las Autoridades Sanitarias realizaban muestreos para detectar portadores mediante pruebas de laboratorio, pero a partir de ese momento, las Administraciones Autonómicas abandonan este procedimiento para establecer la Educación Sanitaria como proceso fundamental para el control de las enfermedades entre los manipuladores de alimentos, relegando a un segundo término las pruebas de laboratorio.

En la actualidad, se realizan controles analíticos periódicos tanto de las materias primas como del producto final sobre una serie de parámetros establecidos (RD 2207/1995). Los resultados obtenidos deberán ser archivados en un documento control.
Igualmente, se tomarán muestras testigos de las materias primas y de los productos elaborados, que serán guardados en recipientes estériles durante 48 horas posteriores a su consumo, para poder analizar en caso de existir alguna incidencia.

\section{REGISTRO Y ENTREGA DE DOCUMENTA- CIÓN PREVENTIVA}

El Servicio de Prevención de Riesgos Laborales (SPRL) cuando se incorpora un trabajador manipulador de alimentos facilita el llamado "manual de bienvenida ", a través del cual documenta y registra la información y formación preventiva necesaria para su trabajo.

El manual consta de:

- Información sobre " Higiene alimentaria”.

- Información básica en Prevención de Riesgos Laborales (PRL), accidente de trabajo, enfermedad profesional y emergencias .

- Formación básica en PRL

- Formación específica para manipuladores de alimentos según Decreto 10/2001 del 25 de Enero.

- Información sobre hábitos higiénicos personales.

- Información-Formación para cumplimentar Check-list interno supervisado por personal del Servicio de Prevención (Anexo I).

- Información sobre controles analíticos de las instalaciones, equipos de trabajo y alimentos.

- Información sobre recogida de muestras testigo.

Se oferta la vigilancia de la salud (protocolo de manipulador de alimentos)

Se recomienda vacunación antigripal

Periódicamente (cada dos años como máximo cada cuatro) el SPRL oferta a cada trabajador

- Información sobre "Higiene alimentaria".

- Información básica en PRL.

- Formación básica en PRL 
- Formación en manipuladores de alimentos según Decreto 10/2001 del 25 de Enero.

- Recordatorio pautas de check-list

- Recordatorio información sobre controles analíticos de las instalaciones, equipos de trabajo y alimentos.

- Recordatorio información sobre hábitos higiénicos personales.

- Recordatorio sobre recogida de muestras testigo

- Vigilancia de la salud.

\section{ACTUACION ANTE SOSPECHA DE UN BROTE DE TOXIINFECCION ALIMENTA- RIA}

La legislación actual que regula esta materia. Se recoge en la Resolución del 22 de diciembre de 1981 de la Dirección General de Salud Pública, donde se específica la lista de Enfermedades de Declaración Obligatoria y en el R.D. 2050/1982 del 30 de julio por el que se contempla el reglamento de lucha contra las enfermedades infecciosas.

Aunque estas normativas legales son de carácter nacional, las competencias en materia de vigilancia epidemiológica han sido transferidas a los Departamentos de Salud de las Comunidades Autónomas, por lo que es necesario conocer la reglamentación específica de la Comunidad donde se encuentre uno ejerciendo como profesional.

A este respecto, y en concreto para la Comunidad Autónoma de Madrid (CAM), la Normativa para la notificación de enfermedades de declaración Obligatoria se encuentra regulada por el Decreto 143/1985 del 20 de Diciembre de 1985, clasificando la toxinfección alimentaria dentro de este grupo de enfermedades notificables.

Los médicos con ejercicio profesional en la Comunidad de Madrid, están obligados a declarar la existencia o sospecha de alguna de las enfermedades de declaración obligatoria, así como la detección de todo brote epidémico presumiblemente relacionado con una toxinfección alimentaria, y el incumplimiento de estas obligaciones, tanto para el personal médico como para el empresario, podrán ser sancionadas de acuerdo con la normativa vigente.
De esta forma, cuando se detectan dos o más casos con un cuadro clínico semejante que aparecen después de consumir un mismo alimento (Brote Epidemiológico) se procederá a realizara sin demora la notificación del brote, que deberá hacerse a las Autoridades sanitarias de forma urgente y en menos de 24 horas.

Como estos brotes pueden surgir en centros donde existen comedores colectivos (empresas, colegios, residencias de ancianos,) ha de ser el propio centro quien comunique esta incidencia directamente a la autoridad sanitaria o al médico del Centro para que a su vez lo comunique a la Autoridad Sanitaria.

Con independencia de la normativa obligatoria que exige la declaración ante sospecha de un brote epidemiológico, existen motivos desde el punto de vista sanitario que debemos tenerlos en consideración a la hora de entender la importancia que en sí misma supone la medida de "notificación inmediata $y$ ante sospecha"

- Un brote epidémico puede ser la primera manifestación de una epidemia que de no ser controlada a tiempo, pudiera llegar a alcanzar grandes dimensiones.

- La información recibida de forma puntual e inmediata puede ayudar a identificar las causas que lo han motivado y a tomar las medidas de control adecuado a corto, medio y largo plazo

- Puede conocer desde el primer momento y por tanto, con menor margen de error, cuando y donde se han obtenido las materias primas, como se han transportado, técnicas y utensilios utilizados en la elaboración de los alimentos, procedimientos de almacenamiento, productos utilizados o añadidos durante la preparación, cantidad de alimentos elaborados, identificación de comensales, fecha de elaboración, distribución, consumo de los productos y valoración de las condiciones higiénico-sanitarias de los locales, entre otros muchos datos de interés sanitario que pueden ser identificados en los primeros momentos y que a medida que avanza el tiempo, pueden ir desapareciendo. 
De esta forma, una vez notificada la sospecha del brote, la autoridad sanitaria procede mediante un protocolo establecido a enviar técnicos a diferentes puntos diana que se encargarán de realizar la investigación correspondiente y el estudio del brote.

Aunque no en todas las investigaciones de brotes epidemiológicos se pueden llegar a establecer las causas biológicas o aislar los gérmenes responsables, en la gran mayoría de los casos se logra identificar los puntos de la cadena alimenticia donde se haya podido producir algún error. En definitiva, la actuación temprana permite con mayor facilidad confirmar o no la existencia del brote, y permite emitir el informe técnico donde queden reflejados todos los pasos, resultados y conclusiones de la investigación, así como las medidas correctoras que deban adoptarse.

\section{CONCLUSIÓN}

Después de analizar cada uno de los puntos implicados es fundamental:

- El control higiénico en cada uno de los pasos de la cadena alimenticia, desde su inicio (materia prima) hasta su consumo.

- La implicación de toda la cadena de mando desde el empresario/dirección/gerencia hasta el último trabajador manipulador de alimentos.

- La concienciación y responsabilidad de los manipuladores de alimentos en la transmisión de enfermedades a terceros por malos hábitos en la realización de sus tareas.

No se produce un brote por mera casualidad, sino que tiene que concurrir al unísono varios factores de riesgo.

\section{MARCO LEGAL}

1. Ley 14/1986 del 25 de Abril, General de Sanidad, establece en el artículo 3.1, que los medios y actuaciones del sistema sanitario están orientados a promover la salud.. En el art. 24, 25 y 26 faculta a los órganos competentes en esta materia y las medidas a adoptar.

2. $\mathrm{RD} 2817 / 1983$ de 13 de octubre, por el que se aprueba la Reglamentación Técnico-Sanitaria de los comedores colectivos (B.O.E. de 11 de noviembre de 1983).

3. RD $2207 / 1995$ de 28 de diciembre, por el que se establecen las normas de higiene relativas a los productos alimenticios, incorporada de la Directiva 93/43/CEE del 14 de junio.

4. RD 202/2000 de 11 de febrero, por el que se establecen las normas relativas a los manipuladores de alimentos.

5. RD $3484 / 2000$ de 29 de diciembre, por el que se establecen, las normas de higiene para la elaboración distribución y comercio de comidas preparadas.

6. BOCM. Decreto 10/2001, de 25 de enero por el que se establecen las normas relativas a la formación de los manipuladores de alimentos, autorización, control y supervisión de los centros y programas de formación de la Comunidad de Madrid.

7. BOCM Orden $73 / 2002$ de 30 de enero, por el que se establecen medidas complementarias relativas a la formación de manipuladores de alimentos autorización, control y supervisión de los centros y programas de formación de la Comunidad de Madrid.

8. Ordenanza Reguladora de las Condiciones Higiénico-Sanitarias y protección de los consumidores en establecimientos donde se consumen comidas y bebidas. (28 de febrero de 1990) del Ayuntamiento de Madrid. 
ANEXO I

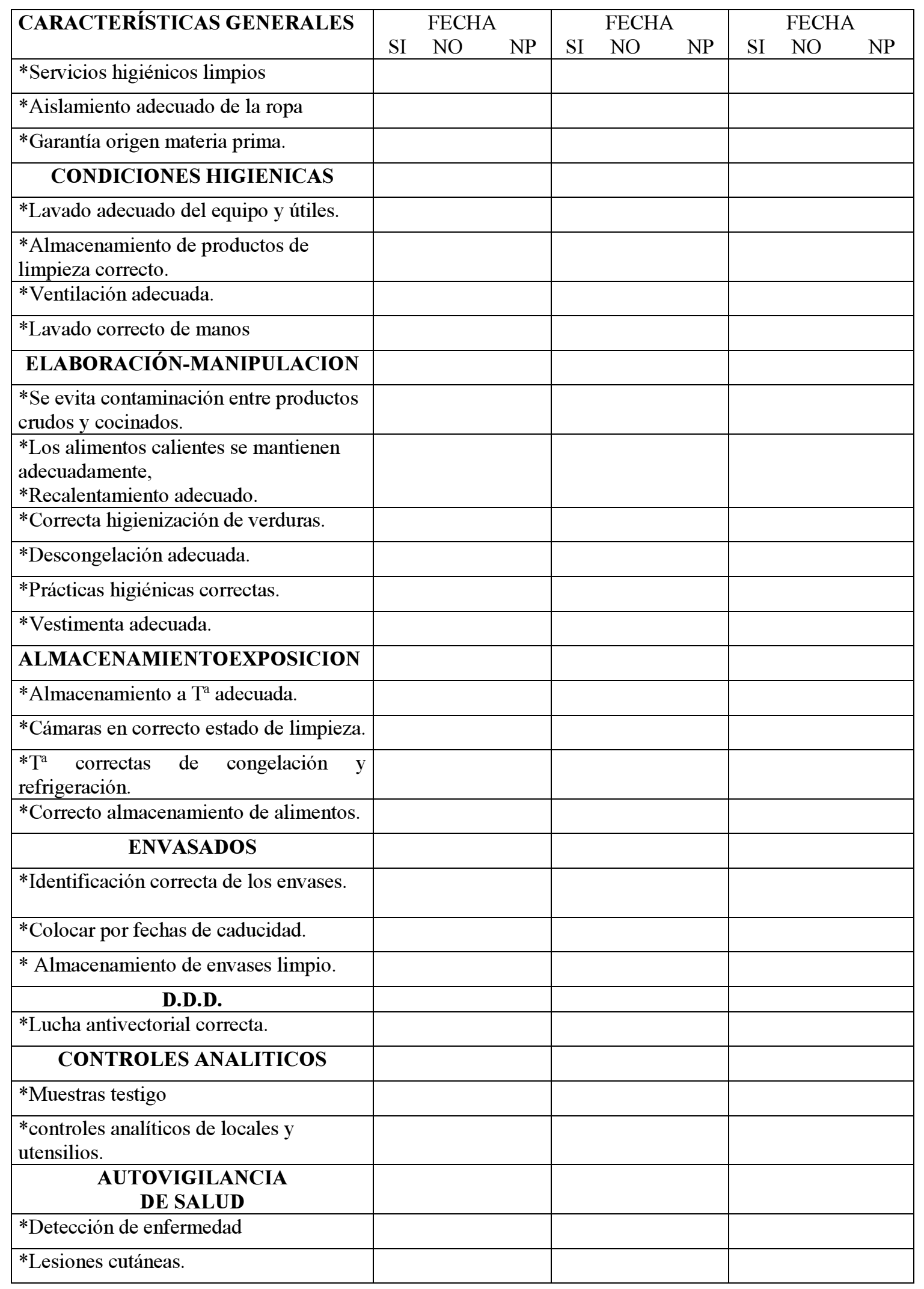




\section{BIBLIOGRAFÍA}

Ley 14/1986 del 25 de Abril, General de Sanidad.

RD 2817/1983 de 13 de octubre.

RD 3484/2000 de 29 de diciembre.

Decreto 10/2001, de 25 de enero de la CAM.

Pruebas rápidas en el control de puntos críticos. Concepción Blanco. Laboratorio regional de Salud Pública .Consejería de Salud. CAM.

Evaluaciones por análisis de peligros en puntos críticos de control: guía para identificar peligros y evaluar riesgos relacionados con la preparación y la conservación de alimentos. Bryan, Frank L. Ginebra; Organización Mundial de la Salud; 1992. 86 p

Alimentaria: Revista de tecnología e higiene de los alimentos, ISSN 0300-5755, No 320, 2001 , pags. 33-34 . J. C. Domínguez, F. Rodríguez, J. Oballe

Manipulación correcta de los alimentos: guía para gerentes de establecimientos de servicios de alimentación. Jacob, Michael. Organizacíon Mundial de la Salud; 1990. 160 p

Contaminación de los alimentos por virus: un problema de salud pública poco comprendido. Carlos K. B. Ferrari y Elisabeth A. F. S. Torres ${ }^{2}$. Rev Panam Salud Publica vol. 3 n. 6 Washington June 1998

Guía para el diseño, implantación y mantenimiento de un sistema APPCC y prácticas correctas de higiene en las empresas alimenticias. Documentos Técnicos de Salud Pública n ${ }^{\circ} 116$. 